\title{
Miriam Bernard and Thomas Scharf (eds.) (2007). Critical Perspectives on Ageing Societies. Bristol: The Policy Press, Ageing and the Lifecourse Series, 200 pp. ISBN 978186134 8906 (paperback)
}

\author{
REVIEWED BY LIAM FOSTER*
}

The first in a new series of Ageing and the Life Course texts by Policy Press, Critical Perspectives on Ageing Societies, edited by Miriam Bernard and Tom Scharf, brings together some of the leading experts in the field of gerontology from Britain and North America to consider how the current context of critical gerontology has developed over the last 25 years and discuss the future challenges it faces. In the foreword, Chris Phillipson reminds us how, with its roots in political economy, feminist and humanist foundations, critical gerontology has brought a greater appreciation of the links between ageing and cultural and economic characteristics in later life and the impact of social policy. He continues that this was particularly important during the Thatcherite regime with the emergence of "an ideologically driven critique of demographic change, with the labelling of older people as a 'burden' and 'cost' to society' (p. vii). This was combined with a reduction in the quality and scope of services. These debates still continue to permeate social policy (and wider society) with concerns about increasing longevity, rising pension deficits and a potential 'demographic time bomb'. It is within this context that critical gerontology has so much

* Liam Foster, University of Sheffield, UK. 
International Journal of Ageing and Later Life

to offer, not least through a commitment to scholarship that gives older people an integral role in the research process, a notion advocated in this collection in the works of Mo Ray and Bill Bytheway and colleagues, amongst others. Furthermore, population changes that have created greater economic and cultural diversity among older people have brought new challenges that need to be addressed. Indeed, the authors in this collection bring new visions to the challenges that warrant further investigation, perhaps elsewhere in the series.

Following the introduction by Bernard and Scharf, where we are reminded that ageing is a life course issue rather than something which only affects "the tribe of the elderly" (p. 3), the collection is divided into three parts, the first of which contains three chapters which introduce some of the historical, theoretical and policy concerns surrounding older people. Martha Holstein and Meredith Minkler consider notions of autonomy, empowerment and "successful ageing" though remain critical of ideas based purely on medical models. Robin Means develops these ideas within a policy arena in the third chapter where he cites "the failure of first Conservative, and then Labour governments to back social services as the lead agency for community care" (p. 50) and criticises the 2005 White Paper which stresses the importance of reducing discomfort and stress, especially of older "patients" (rather than service users). He argues that the main target of the White Paper is rather a reduction in emergency bed delays. He continues that policy developments have largely been to the detriment of older people through the use of the medical model. Sandwiched in between these chapters is one of Peter Townsend's last works. Townsend, in his irrepressible style, deals with the historical development of critical gerontology (to which he had such a major role to play) with its routes in structured dependency and political economy, advocating the importance of a human rights approach to the study of ageing as a crucial basis for anti-oppressive practice. This completes an interesting section that would, perhaps, have benefited from the addition of further policy context, in particular in relation to a political economy analysis of pensions and savings.

The four chapters in the next section of the book focus on methodological debates within critical gerontology. It is evident here that there is a commitment to extending the conceptual approach to ageing, both 
methodologically and practically. For instance, the importance of narrative gerontology is emphasised in the work of Ruth Ray, while Mo Ray debates the merits of the "real" involvement of older people in research. She argues that research on marginalised and underrepresented groups should be action orientated. Furthermore, it is not just about changing how people think about ageing but how they feel. Using archived longitudinal data the place of "re-studies" is put forward by Julia Johnson, Sheena Rolph and Randall Smith. The last refuge re-visited neatly highlights some of the constraints in social research and discusses key methodological considerations such as anonymity versus ownership. The ethical issues are particularly interesting and areas I draw upon in my own teaching of research methods. Bill Bytheway, Richard Ward, Caroline Holland and Sheila Peace discuss, through employing participatory methods, how policies designed to tackle age discrimination may become overtly associated with employment practices. They also ask what role researchers play in the distillation of their results, questioning their own roles and identities as well as raising questions about how "old" or "older" is defined in gerontological research.

Building upon issues touched upon earlier in the book, the third and final section addresses some of the challenges faced by critical gerontologists. In particular, they ask what we can learn from what has already been achieved as well as the challenges that lie ahead. Rick Moody concentrates on the notion of ethics and justice rather than conflict between generations posing insightful questions about social justice and entitlements - a theme which fits neatly with the life course perspective. Tony Warnes and Judith Phillips outline some of the challenges to gerontology as a distinct discipline. These include the tendency for politicians, particularly under a Conservative government, to place more emphasis on traditional long-established subjects rather than critical gerontology. They go on to outline some of the benefits a multidisciplinary approach may have in the study of ageing. Finally they conclude that although gerontology has come a long way over the last 60 years, it "still needs to anchor its status as a discipline if it is not to lose ground to "medicine, nursing and social work in setting future research, policy and practice agendas'" (p. 153). Wise words indeed! 
International Journal of Ageing and Later Life

Given that many of these chapters draw on the 2005 British Society of Gerontology Annual conference, which I was fortunate to attend, I was expecting an enjoyable read and was not disappointed. However, I was also impressed at how well the editors, Miriam Bernard and Thomas Scharf, have been able to bring these papers together in a logical and coherent manner. Furthermore, the contribution of the eminent British scholars is complemented by humanist and feminist perspectives advocated by Martha Holstein and Meredith Minkler, Ruth Ray and Rick Moody, highlighting the importance of North American contributions to critical gerontology debates. Despite being a relatively short text, under 200 pages, it is surprising how much information this collection covers. I have no doubt that it will provide a valuable text for gerontological researchers and students alike. 